\title{
Microtubule motors: moving forward on many fronts Viki Allan
}

Address: Faculty of Life Sciences, University of Manchester, The Michael Smith Building, Oxford Road, Manchester M13 9PT, UK

Email: viki.allan@manchester.ac.uk

Fl000 Biology Reports 2009, I:52 (doi:10.34I0/BI-52)

The electronic version of this article is the complete one and can be found at: http://FI000.com/Reports/Biology/content///52

\begin{abstract}
Microtubule motors drive the movement of many different cargoes in eukaryotic cells. A combination of in vitro and in vivo approaches has led to a better understanding of their mechanism of action and function and are also revealing that the microtubule track itself may have an important role to play in directing cargo movement within the cell.
\end{abstract}

\section{Introduction and context}

When you look at a living eukaryotic cell by light microscopy, what strikes you is that everything in the cell is moving, often over considerable distances. Much of this motility is driven by microtubule motors, which use the energy from ATP hydrolysis to walk along microtubules, which are linear polymers made up of $\alpha / \beta$-tubulin dimers. A wide range of cargoes, including membrane-bound organelles, chromosomes, mRNA, and microtubules themselves, are transported by these motors.

There are two families of microtubule motors: the dyneins and kinesins. Dyneins move toward the minus end of microtubules, which are found in the centre of cells such as fibroblasts, with cytoplasmic dynein-1 (referred to as dynein from now on) driving most minus end-directed membrane movement. Many kinesins, including the founding member kinesin-1, translocate toward the rapidly growing and shrinking plus ends, which are usually oriented toward the cell periphery. However, dynein regularly takes backward steps, at least when single purified motor molecules are analysed [1-3], and kinesin- 1 can also step backward under a load $[2,4]$. This flexibility may help motors get around obstacles in the cell. Here, I review some recent key advances and controversies surrounding dynein and kinesin-1 function in the cell.

\section{Major recent advances One motor or more?}

In vitro assays have proven extremely useful for the analysis of the force generation and stepping mechanisms of single motor molecules. However, in the cell, it is likely that multiple motor proteins work together to move each cargo. A key property of each motor is its processivity, which is the number of steps it takes along the microtubule before it dissociates. While single dynein or kinesin-1 molecules move artificial cargoes such as beads $1-2 \mu \mathrm{m}$ along microtubules in vitro, this distance is considerably increased when multiple motors are attached to the bead $[2,5]$. The number of dynein molecules assembled onto messenger ribonucleoprotein (mRNP) particles is thought to influence both the rate and duration of their translocations in Drosophila embryos [6]. Similar conclusions have been reached for both kinesin-1- and dynein-driven peroxisome movement in vivo in Drosophila S2 cells [7]. Based on the existence of clear steps in the velocity histogram, Kural and colleagues [7] proposed that each active motor contributes approximately $1.2 \mu \mathrm{m} / \mathrm{sec}$, meaning that 10 motors would be needed to generate the maximum rate of $12 \mu \mathrm{m} / \mathrm{sec}$. However, this interpretation is complicated by the fact that microtubule sliding and buckling within the cytoplasm can also generate rapid peroxisome movement [8]. Moreover, a recent study of lipid droplets in Drosophila embryos demonstrated that the number of 
kinesin-1 molecules engaged had no effect on either the length of movement or its rate [9]. Although the control of motor number may play a part in regulating cargo movement, it cannot be the only mechanism. Instead, associated proteins could modulate motor activity or the microtubule track itself could affect translocation efficiency. Both possibilities are discussed below.

\section{Accessory proteins as regulators}

It has long been thought that a dynein-associated complex called dynactin acts to improve dynein's processivity, making it similar to that of kinesin-1 [10]. Dynactin can bind to microtubules via two regions in its N-terminal domain of its p150 subunit: the CAP-Gly and basic domains [11-13]. Data from in vitro assays have suggested that the CAP-Gly domain may act as an anchor, while the basic domain allows p150 to 'skate' along the microtubule [12], providing an attractive mechanism for enhancing dynein's processivity.

This model has been brought into question by an in vivo study that used RNA interference (RNAi) knockdown to remove wild-type p150, which was replaced by $\mathrm{p} 150$ lacking its microtubule-binding domains [14]. This strategy revealed that microtubule binding was not needed for processive movement of peroxisomes or mRNPs [14]. This result has since been confirmed for dynein-dependent Golgi apparatus positioning [15]. The absence of p150's microtubule-binding regions did affect microtubule organisation, however [14], and the ability of dynactin to bind to microtubule plus ends [15]. Studies in Saccharomyces cerevisiae suggest that dynactin's microtubule function is critical when dynein needs to generate large amounts of force, such as when moving the nucleus into the bud neck, but that it is not required to drive microtubule sliding across the cell cortex [16]. Interestingly, natural splice forms of p150 that lack the microtubule-binding domains exist, suggesting that there may be subsets of dynactin complexes that perform different roles in the cell. That dynactin containing truncated p150 can still enhance dynein's processivity has been confirmed using recombinant dynein and dynactin purified from S. cerevisiae [16]. Perhaps the binding of dynactin p150 to the dynein intermediate chain is sufficient to improve dynein's function, even in the absence of dynactin-microtubule interactions: how this activation is achieved remains to be determined.

There is no known equivalent of the dynactin complex for kinesin-1, but instead the binding of kinesin-1 to cargo may activate the motor by unfurling it from its folded inactive cytosolic state, in which the C-terminal domain of the kinesin heavy chain (KHC) interacts with and inhibits the $\mathrm{N}$-terminal motor domain [17-19]. It seems that both the heavy and light chains of kinesin-1 need to interact with cargo molecules or accessory factors for the motor to be fully activated $[20,21]$. Furthermore, the specific cargo protein that binds kinesin-1 may affect motor properties since vesicles containing alcadein- $\alpha$ move at a faster rate than those containing amyloid $\beta$-protein precursor [22]. Cargo-associated proteins may also toggle motors between active and inactive states since the direct binding of the mitochondrial protein Miro to the motor domain of kinesin- 1 in the presence of calcium prevents kinesin binding to microtubules [23]. This may explain how changes in intracellular calcium caused by glutamate receptor activation lead to accumulation of mitochondria at synapses [24]. Likewise, the activity of the heterogeneous nuclear ribonucleoprotein Squid is needed to switch mRNP particles from a motile state to dynein-dependent anchoring in Drosophila oocytes [25].

In an interesting twist, kinesin-1 activity may be regulated by molecules that are associated with the microtubule track rather than the cargo since a microtubule-associated protein (MAP) named ensconsin is required for motility of full-length KHC in Drosophila embryo extracts, whereas its absence has no effect on a constitutively active truncated version of KHC [26]. One interpretation is that ensconsin somehow plays a part in the unfolding and activation of kinesin- 1 , which is a very surprising function for a MAP.

\section{Not all tracks are the same}

While ensconsin may promote kinesin- 1 motility, other MAPs, including the neuronal MAP tau, have been shown to compromise motor function. Kinesin- 1 is sensitive to much lower concentrations of tau than dynein, and tau tended to cause kinesin-1 detachment $[5,27]$ whereas dynein tended to reverse when encountering a patch of tau [27]. The distribution of MAPs in a cell therefore might influence which motors use specific tracks effectively. This is supported by the apparent preference of trans-Golgi network (TGN)-derived secretory vesicles for a subclass of septin-2-associated microtubules in epithelial cells, where septin 2 is thought to promote motility by clearing those microtubules of MAP4 [28]. Interestingly, the Golgi apparatus itself can serve as a nucleation site for microtubules via the activity of the A-kinase anchoring protein (AKAP450) [29] and these Golgi-nucleated microtubules are stabilised at their plus ends by a microtubule plus end-binding protein, CLASP2 (cytoplasmic linker-associated protein 2) [30]. Whether these microtubules are preferential tracks for vesicles moving away from the Golgi apparatus and how these microtubules relate to septin-2-associated microtubules remains to be established. 
The presence of septin 2 also marks out those microtubules that are modified by polyglutamylation [28], which along with acetylation, polyglycylation, and detyrosination form a series of reversible post-translational modifications that are found on subpopulations of microtubules [31]. There is accumulating evidence that these modified microtubules may be preferred tracks for kinesin-1 [31-34] because KHC has a higher affinity for microtubules containing acetylated and detyrosinated $\alpha$-tubulin and for polyglutamylated/polyglycylated $\beta$-tubulin [33]. Intriguingly, the acetylated lysine is thought to be in the lumen of the microtubule, suggesting that changes in the interior can lead to alterations in the exterior of the microtubule lattice. In Aspergillus nidulans, however, kinesin-1 showed no preference for stable detyrosinated microtubules, whereas a kinesin-3 family member did [35]. Likewise, in mice lacking a subunit of tubulin polyglutamylase, it was a kinesin-3 rather than kinesin- 1 or -2 that was mislocalised [36]. This suggests that the cell type and situation (and possibly even cargo) may influence which microtubules are preferred tracks.

Why might a choice of track be important? In a small non-polarised cell, it may not be that critical, but in a moving cell, it might be advantageous to be able to load vesicles budding from the Golgi onto microtubules that lead directly to the leading edge, thus facilitating cell extension and migration. Furthermore, when epithelial cells are undergoing polarisation and then maintaining that state, it may help to separate microtubules that lead to the apical versus the basolateral surface. In this regard, it is interesting that two different populations of microtubules have been observed in polarised MDCK cells [37] and that septin 2 expression is needed for these cells to polarise in the first place [28]. Distinctly modified microtubules may also underlie the initial differentiation of neurites into axons or dendrites by encouraging selective transport of certain cargoes, such as JIP1-containing structures, by kinesin-1 along a single neurite, leading to that neurite becoming the axon (for example, $[33,38,39])$. It is not yet clear what determines whether specific cargoes move preferentially into the mature dendrites or axon, but microtubule modification, MAPs, and plus end-binding proteins have all been suggested to play a part, along with the motor itself and the cargo to which it is bound $[33,36,38-43]$.

\section{Future directions}

There are many questions left unanswered about how microtubule motors work in the cell. For example, the regulation of the activity of individual motors is still poorly understood. Moreover, understanding how multiple motors, particularly those of opposite polarity, work together when on a single cargo is a huge challenge. For example, do such motors engage in a tug-of-war to determine in which direction a cargo moves or are their activities switched on and off coordinately [44]? Here, we may well find that the answers vary according to the particular cargo. Recent in vivo studies have often led us to reassess what we thought we had learned about this issue from the use of single-molecule in vitro assays. It is an exciting time for motors though, as their roles in brain development and function, such as the requirement for kinesin-1 activity in learning, are becoming uncovered [45]. Their importance is further underscored by the extensive links between motor malfunction and disease [46-48].

\section{Abbreviations}

AKAP450, A-kinase anchoring protein 450; CAP, cytoskeleton associated protein; CLASP2, cytoplasmic linkerassociated protein 2; Gly, glycine; JIP1, Jun $\mathrm{NH}_{2}$-terminal kinase (JNK) interacting protein 1; KHC, kinesin heavy chain; MAP, microtubule-associated protein; MDCK, Madin Darby canine kidney; mRNP, messenger ribonucleoprotein; RNAi, RNA interference; TGN, trans-Golgi network.

\section{Competing interests}

The author declares that she has no competing interests.

\section{Acknowledgements}

Work in the author's laboratory is supported by the Biotechnology and Biological Sciences Research Council, the Medical Resesarch Council and the Wellcome Trust.

\section{References}

I. Wang Z, Khan S, Sheetz MP: Single cytoplasmic dynein molecule movement: characterization and comparison with kinesin. Biophys J 1995, 69:2011-23.

2. Mallik R, Petrov D, Lex SA, King SJ, Gross SP: Building complexity: an in vitro study of cytoplasmic dynein with in vivo implications. Curr Biol 2005, I 5:2075-85.

3. Ross JL, Wallace K, Shuman H, Goldman YE, Holzbaur EL: Processive bidirectional motion of dynein-dynactin complexes in vitro. Nat Cell Biol 2006, 8:562-70.

FI000 Factor 3.0 Recommended Evaluated by Viki Allan 0I Jun 2006

4. Carter NJ, Cross RA: Mechanics of the kinesin step. Nature 2005, 435:308-I2.

FI000 Factor 4.8 Must Read

Evaluated by Hernando Sosa 25 May 2005, Ilan Davis 26 May 2005

5. Vershinin M, Carter BC, Razafsky DS, King SJ, Gross SP: Multiplemotor based transport and its regulation by Tau. Proc Natl Acad Sci U S A 2007, 1 04:87-92.

6. Bullock SL, Nicol A, Gross SP, Zicha D: Guidance of bidirectional motor complexes by mRNA cargoes through control of dynein number and activity. Curr Biol 2006, I6:1447-52.

FI000 Factor 3.0 Recommended

Evaluated by Anna Akhmanova 29 Aug 2006 
7. Kural C, Kim H, Syed S, Goshima G, Gelfand VI, Selvin PR: Kinesin and dynein move a peroxisome in vivo: a tug-of-war or coordinated movement? Science 2005, 308:|469-72.

FI000 Factor 4.8 Must Read

Evaluated by David Stephens 0I Jun 2005, Vladimir Rodionov 14 Sep 2005

8. Kulic IM, Brown AE, Kim H, Kural C, Blehm B, Selvin PR, Nelson PC, Gelfand $\mathrm{VI}$ : The role of microtubule movement in bidirectional organelle transport. Proc Natl Acad Sci U S A 2008, I 05: I00 I I-6.

9. Shubeita GT, Tran SL, Xu J, Vershinin M, Cermelli S, Cotton SL, Welte MA, Gross SP: Consequences of motor copy number on the intracellular transport of kinesin-1-driven lipid droplets. Cell 2008, 135:1098-107.

10. King SJ, Schroer TA: Dynactin increases the processivity of the cytoplasmic dynein motor. Nat Cell Biol 2000, 2:20-4.

II. Kobayashi T, Shiroguchi K, Edamatsu M, Toyoshima YY: Microtubule-binding properties of pI50 expedient for dynein motility. Biochem Biophys Res Commun 2006, 340:23-8.

12. Culver-Hanlon TL, Lex SA, Stephens AD, Quintyne NJ, King SJ: A microtubule-binding domain in dynactin increases dynein processivity by skating along microtubules. Nat Cell Biol 2006, 8:264-70.

FI000 Factor 3.2 Recommended

Evaluated by Anna Akhmanova 16 Feb 2006, David Stephens 20 Feb 2006

13. Waterman-Storer CM, Karki S, Holzbaur EL: The pI50Glued component of the dynactin complex binds to both microtubules and the actin-related protein centractin (Arp-I). Proc Natl Acad Sci U S A 1995, 92:1634-8.

14. Kim H, Ling SC, Rogers GC, Kural C, Selvin PR, Rogers SL, Gelfand VI: Microtubule binding by dynactin is required for microtubule organization but not cargo transport. J Cell Biol 2007, I 76:64 I-5I.

FI000 Factor 6.4 Must Read

Evaluated by David Stephens 0I Mar 2007, Viki Allan 16 Mar 2007

15. Dixit R, Levy JR, Tokito M, Ligon LA, Holzbaur EL: Regulation of dynactin through the differential expression of pl50Glued isoforms. J Biol Chem 2008, 283:336 II-9.

16. Kardon JR, Reck-Peterson SL, Vale RD: Regulation of the processivity and intracellular localization of Saccharomyces cerevisiae dynein by dynactin. Proc Natl Acad Sci U S A 2009, I 06:5669-74.

17. Coy DL, Hancock WO, Wagenbach M, Howard J: Kinesin's tail domain is an inhibitory regulator of the motor domain. Nat Cell Biol 1999, I:288-92.

18. Friedman DS, Vale RD: Single-molecule analysis of kinesin motility reveals regulation by the cargo-binding tail domain. Nat Cell Biol 1999, I:293-7.

19. Stock MF, Guerrero J, Cobb B, Eggers CT, Huang TG, Li X, Hackney DD: Formation of the compact confomer of kinesin requires a $\mathrm{COOH}$-terminal heavy chain domain and inhibits microtubule-stimulated ATPase activity. I Biol Chem 1999, 274: |46|7-23.

20. Blasius TL, Cai D, Jih GT, Toret CP, Verhey KJ: Two binding partners cooperate to activate the molecular motor kinesin-I. J Cell Biol 2007, I 76: I I-7.

FI000 Factor 3.0 Recommended

Evaluated by Viki Allan 19 Jan 2007

21. Woźniak MJ, Allan VJ: Cargo selection by specific kinesin light chain I isoforms. EMBO J 2006, 25:5457-68.

22. Araki Y, Kawano T, Taru H, Wada S, Miyamoto K, Kobayashi H, Ishikawa H, Ohsugi Y, Yamamoto T, Matsuno K, Kinjo M, Suzuki T: The novel cargo alcadein induces vesicle association of
kinesin-I motor components and activates axonal transport. EMBO J 2007, 26:1475-86.

23. Wang $X$, Schwartz TL: The mechanism of $\mathrm{Ca}^{+}$-dependent regulation of kinesin-mediated mitochondrial motility. Cell 2009, I36:163-74

FI000 Factor 6.0 Must Read

Evaluated by David Stephens 26 Jan 2009

24. MacAskill AF, Rinholm JE, Twelvetrees AE, Arancibia-Carcamo IL, Muir J, Fransson A, Aspenstrom P, Attwell D, Kittler JT: Mirol is a calcium sensor for glutamate receptor-dependent localization of mitochondria at synapses. Neuron 2009, 6 I:54 I-55.

FI000 Factor 6.0 Must Read Evaluated by Michael Ehlers 18 Mar 2009

25. Delanoue R, Herpers B, Soetaert J, Davis I, Rabouille C: Drosophila squid/hnRNP helps dynein switch from a gurken mRNA transport motor to an ultrastructural static anchor in sponge bodies. Dev Cell 2007, I3:523-38.

FI000 Factor 3.2 Recommended

Evaluated by Elizabeth Gavis 31 Oct 2007, David Ish-Horowicz 19 Nov 2007

26. Sung HH, Telley IA, Papadaki P, Ephrussi A, Surrey T, Rørth P: Drosophila ensconsin promotes productive recruitment of kinesin-I to microtubules. Dev Cell 2008, 15:866-76.

27. Dixit R, Ross JL, Goldman YE, Holzbaur EL: Differential regulation of dynein and kinesin motor proteins by tau. Science 2008, 319:1086-9.

28. Spilotis ET, Hunt SJ, Hu Q, Kinoshita M, Nelson WJ: Epithelial polarity requires septin coupling of vesicle transport to polyglutamylated microtubules. J Cell Biol 2008, 180:295-303.

FI000 Factor 6.7 Must Read

Evaluated by Keith Mostov 23 Jan 2008, David Stephens 24 Jan 2008,

Trina Schroer 25 Jan 2008, Alexander Bershadsky 31 Mar 2008, Irina Kaverina 28 Apr 2008

29. Rivero S, Cardenas J, Bornens M, Rios RM: Microtubule nucleation at the cis-side of the Golgi apparatus requires AKAP450 and GMI30. EMBO J 2009, 28:1016-28.

FI000 Factor 3.0 Recommended

Evaluated by Richard Rachubinski 29 Apr 2009

30. Efimov A, Kharitonov A, Efimova N, Loncarek J, Miller PM, Andreyeva N, Gleeson P, Galjart N, Maia AR, McLeod IX, Yates JR 3rd, Maiato $H$, Khodjakov A, Akhmanova A, Kaverina I: Asymmetric CLASP-dependent nucleation of noncentrosomal microtubules at the trans-Golgi network. Dev Cell 2007, 12:917-30.

FI000 Factor 7.I Must Read

Evaluated by David Stephens II Jun 2007, Michael Ehlers 12 Jun 2007, Claire Walczak 20 Jun 2007, Ed Manser 0 I Aug 2007, Vladimir Rodionov 03 Oct 2007, Kenneth Sawin 17 Jul 2008

31. Verhey KJ, Gaertig J: The tubulin code. Cell Cycle 2007, 6:2 I52-60.

32. Lin SX, Gundersen GG, Maxfield FR: Export from pericentriolar endocytic recycling compartment to cell surface depends on stable, detyrosinated (glu) microtubules and kinesin. Mol Biol Cell 2002, I3:96-109.

33. Reed NA, Cai D, Blasius TL, Jih GT, Meyhofer E, Gaertig J, Verhey KJ Microtubule acetylation promotes kinesin-I binding and transport. Curr Biol 2006, 16:2166-72.

FI000 Factor 3.0 Recommended

Evaluated by Anna Akhmanova 06 Dec 2006

34. Dunn S, Morrison EE, Liverpool TB, Molina-París C, Cross RA, Alonso MC, Peckham M: Differential trafficking of Kif5c on 
tyrosinated and detyrosinated microtubules in live cells. J Cell Sci 2008, I 21:1085-95.

35. Zekert N, Fischer R: The Aspergillu nidulans kinesin-3 UncA motor moves vesicles along a subpopulation of microtubules. Mol Biol Cell 2009, 20:673-84.

36. Ikegami K, Heier RL, Taruishi M, Takagi H, Mukai M, Shimma S, Taira S, Hatanaka K, Morone N, Yao I, Campbell PK, Yuasa S, Janke C, Macgregor GR, Setou M: Loss of alpha-tubulin polyglutamylation in ROSA22 mice is associated with abnormal targeting of KIF IA and modulated synaptic function. Proc Natl Acad Sci U S A 2007, 104:3213-8.

37. Jaulin F, Xue X, Rodriguez-Boulan E, Kreitzer G: Polarizationdependent selective transport to the apical membrane by KIF5B in MDCK cells. Dev Cell 2007, 13:5 II-22.

FI000 Factor 3.3 Recommended

Evaluated by Jonathan Scholey 22 Oct 2007, Michael Roth 23 Oct 2007, Heike Folsch 30 Oct 2007

38. Jacobson C, Schnapp B, Banker GA: A change in the selective translocation of the kinesin-I motor domain marks the initial specification of the axon. Neuron 2006, 49:797-804.

FI000 Factor 6.6 Must Read

Evaluated by Anna Akhmanova 22 Mar 2006, Hernando Sosa 10 Apr 2006, Michael Kiebler 17 May 2006, Bettina Winckler 16 Jun 2006

39. Dajas-Bailador $F$, Jones EV, Whitmarsh AJ: The JIPI scaffold protein regulates axonal development in cortical neurons. Curr Biol 2008, 18:22I-6.

40. Song AH, Wang D, Chen G, Li Y, Luo J, Duan S, Poo MM: A selective filter for cytoplasmic transport at the axon initial segment. Cell 2009, 136: | | 48-60.

FI000 Factor 6.4 Must Read

Evaluated by Michael Ehlers 25 Mar 2009, Michael Kiebler 08 Apr 2009
4I. Nakata T, Hirokawa N: Microtubules provide directional cues for polarized axonal transport through interaction with kinesin motor head. J Cell Biol 2003, 162:1045-55.

FI000 Factor 6.0 Must Read

Evaluated by Bettina Winckler II Mar 2004

42. Setou M, Nakagawa T, Seog DH, Hirokawa N: Kinesin superfamily motor protein KIFI7 and mLin-10 in NMDA receptorcontaining vesicle transport. Science 2000, 288:1796-802.

43. Setou M, Seog DH, Tanaka Y, Kanal Y, Takei Y, Kawagishi M, Hirokawa N: Glutamate-receptor-interacting protein GRIP I directly steers kinesin to dendrites. Nature 2002, 4I7:83-7.

FI000 Factor 3.2 Recommended

Evaluated by Erika Holzbaur 3I May 2002, Angus Nairn 3 I May 2002

44. Welte MA: Bidirectional transport along microtubules. Curr Biol 2004, I 4:R525-37.

45. Puthanveettil SV, Monje FJ, Miniaci MC, Choi YB, Karl KA, Khandros E, Gawinowicz MA, Sheetz MP, Kandel ER: A new component in synaptic plasticity: upregulation of kinesin in the neurons of the gill-withdrawal reflex. Cell 2008, 135:960-73.

FI000 Factor 6.0 Must Read

Evaluated by Frank Walsh 02 Feb 2009

46. Guzik BW, Goldstein LS: Microtubule-dependent transport in neurons: steps towards an understanding of regulation, function and dysfunction. Curr Opin Cell Biol 2004, 16:443-50.

47. Chevalier-Larsen E, Holzbaur EL: Axonal transport and neurodegenerative disease. Biochim Biophys Acta 2006, 1762:1094-108.

48. Hirokawa N, Takemura R: Molecular motors in neuronal development, intracellular transport and diseases. Curr Opin Neurobiol 2004, 14:564-73. 